\title{
Exploring process options to enhance metal dissolution in bioleaching of Indian Ocean nodules
}

\author{
Amitava Mukherjee, ${ }^{1}$ Ashok M Raichur, ${ }^{1 *}$ Jayant M Modak ${ }^{2}$ and KA Natarajan ${ }^{1}$ \\ ${ }^{1}$ Department of Metallurgy, Indian Institute of Science, Bangalore-560012, India \\ ${ }^{2}$ Department of Chemical Engineering, Indian Institute of Science, Bangalore-560012, India
}

\begin{abstract}
Polymetallic Indian Ocean nodules offer a lucrative resource for valuable strategic metals such as $\mathrm{Cu}$, Co and Ni. A novel bioleaching process using cell-free spent growth medium from a fully-grown culture of a marine organism isolated from the nodules (Bacillus M1) dissolved about $45 \% \mathrm{Co}$, and $25 \% \mathrm{Cu}$ and $\mathrm{Ni}$ at a the pH of 8.2 in $4 \mathrm{~h}$. To enhance metal dissolution, different modifications in the bioleaching process, such as increasing the $\mathrm{pH}$ of the spent growth medium, carrying out leaching in multiple steps, and introducing organic reductant in the leach pulp, were investigated in this study. Increasing the initial $\mathrm{pH}$ of the spent growth medium to above 12 resulted in a $25-30 \%$ increase in dissolution of $\mathrm{Cu}$, $\mathrm{Co}$ and Ni. The $p K_{\mathrm{a}}$ value for the spent growth medium was observed to be in the range of 11.5-12.5. UV-visible spectroscopy of the growth medium at $\mathrm{pH}$ values above 10.0 suggested a change in the structure of complexing phenolic substances present therein. A four-step leaching process using the spent growth medium, each step lasting for about $4 \mathrm{~h}$, was able to bring around $60 \% \mathrm{Cu}$ and $\mathrm{Ni}$ and $85 \% \mathrm{Co}$ in solution. About $85 \% \mathrm{Co}, 90 \% \mathrm{Cu}$ and $60 \% \mathrm{Ni}$ were dissolved in two-stage leaching, in which the bioleached residue was treated with the spent growth medium from Acidithiobacillus thiooxidans in the second cycle. The effects of concentration of starch $(0.1-10 \%)$ as an organic reductant to the spent growth medium were also studied. The dissolution of $\mathrm{Cu}$, $\mathrm{Co}$ and $\mathrm{Ni}$ stabilized at about 80-85\% at a starch concentration of $3 \%$ and did not increase much thereafter.

(C) 2004 Society of Chemical Industry
\end{abstract}

Keywords: bioleaching; polymetallic nodules; Bacillus M1

\section{INTRODUCTION}

In view of the continuing scarcity of land-based mineral resources along with increasing domestic consumption of valuable metals across the globe, development of environment-friendly technologies for exploring some of the alternate resources of metals has become the need of the day. One of these technologies is the use of biotechnology to recover strategic metals such as $\mathrm{Cu}, \mathrm{Ni}$ and $\mathrm{Co}$ from ocean nodules. Manganese and ferromanganese deposits occur extensively as nodules, crusts and pavements in present-day oceans. The nodules are comprised of oxides of manganese and iron together with various valuable metals such as $\mathrm{Cu}, \mathrm{Ni}$ and Co. ${ }^{1}$ Though the economic potential of recovering valuable metals from nodules has long been recognized, still the search is on for an economically favorable as well as environmentally-benign extraction process.

In the recent past, researchers have started looking into bioprocessing as an alternative route of metal recovery from the nodules. A few acidophilic sulfuroxidizing bacteria and the thermophilic Acidianus brierleyi have been employed for leaching valuable metals from the nodules. ${ }^{2}$ Extracting valuable metals by an electrobioleaching process using chemolithotrophs such as Acidithiobacillus ferrooxidans and Acidithiobacillus thiooxidans has also been attempted. ${ }^{3}$ But all these processes often suffer from the limitations of an acidic environment and the application of high thermal energy or electrical energy for recovering a sizeable amount of metals, which makes them economically unattractive.

Since the $\mathrm{Mn}(\mathrm{IV})$ oxide phase in the nodules harbors $\mathrm{Cu}, \mathrm{Co}$ and $\mathrm{Ni}$, bacterial reduction of $\mathrm{Mn}$ (IV) oxide would result in solubilization of these metals. All the $\mathrm{Mn}(\mathrm{IV})$-reducing bacteria isolated so far from seawater, marine sediments and ferromanganese concretions have been found to be heterotrophs. Most of the isolates from Atlantic and Pacific Ocean nodules were found to be aerobes, which could reduce $\mathrm{Mn}$ (IV) aerobically or anaerobically. ${ }^{4-6}$ The microbial ecology of the Indian Ocean nodules with special reference to metal dissolution has not, up to now, been studied in detail.

* Correspondence to: Ashok M Raichur, Department of Metallurgy, Indian Institute of Science, Bangalore - 560012, India

E-mail: amr@met.iisc.ernet.in

(Received 27 October 2003; revised version received 20 January 2004; accepted 30 January 2004) 
Recently, a marine species, Bacillus M1, was isolated from Indian Ocean nodules and found to be able to leach nodules at near neutral $\mathrm{pH}$ and room temperature using the spent growth medium of the isolate; $45 \% \mathrm{Co}$ and $25 \% \mathrm{Cu}$ and $\mathrm{Ni}$ was extracted in about $4 \mathrm{~h}$ at an operating pulp density of $10 \% .{ }^{7}$ Mild operating conditions coupled with faster kinetics and significant metal recoveries are some of the advantages of this bioprocess. However, considering the very low concentration of $\mathrm{Cu}, \mathrm{Co}$ and $\mathrm{Ni}$ in the ocean nodules and high mining costs involved, enhancing the metal dissolution to the maximum becomes essential.

The main objective of the present work was to investigate different process options for augmenting metal dissolution by bioleaching of Indian Ocean nodules using spent growth medium of the marine isolate. One option studied was the effect of modifying the $\mathrm{pH}$ of the spent growth medium on metal dissolution. Another option was the series leaching of nodules in the spent medium in four consecutive steps. In addition, two-step leaching experiments were carried out at pH 2 using $\mathrm{H}_{2} \mathrm{SO}_{4}$ solutions and spent growth medium from acidophiles such as $A$ thiooxidans. A final option was to test the effect of adding organic agents such as starch to the spent growth medium from the cultures of the isolate.

\section{MATERIALS AND METHODS \\ 2.1 Ocean nodules}

Ocean nodules, collected from the bed of the Indian Ocean, were supplied by the National Institute of Oceanography, Goa, India. These were ground in a mortar and pestle and sieved to obtain all appropriate size fractions for the leaching experiments. All the leaching experiments were done with a $-50,+75 \mu \mathrm{m}$ size fraction of nodules containing around $21.83 \%$ $\mathrm{Mn}, 6.4 \% \mathrm{Fe}, 1.14 \% \mathrm{Cu}, 1.15 \% \mathrm{Ni}$ and $0.17 \% \mathrm{Co}$ (all values in $\mathrm{wt} \%$ ). One $\mathrm{g}$ of nodules per $100 \mathrm{~cm}^{3}$ of leach pulp corresponding to a $1 \%$ pulp density contained $44.64 \mathrm{mmol} \mathrm{dm}^{-3} \mathrm{Mn}, 11.42 \mathrm{mmol} \mathrm{dm}^{-3}$ $\mathrm{Fe}, 1.79 \mathrm{mmol} \mathrm{dm}^{-3} \mathrm{Cu}, 1.96 \mathrm{mmol} \mathrm{dm}^{-3} \mathrm{Ni}$ and $0.3 \mathrm{mmol} \mathrm{dm}^{-3}$ Co.

\subsection{Production of cell-free spent growth medium}

A bacterial strain, labeled Bacillus M1, was isolated from the ocean nodules. The details of the isolation and characterization of the bacterium have been reported elsewhere. ${ }^{8}$ An active culture of the organism is being maintained in the laboratory. The culture is streaked periodically to check for contamination. Bacillus M1 was grown in artificial seawater nutrient broth (ASWNB) in $250 \mathrm{~cm}^{3}$ Erlenmeyer flasks at $30^{\circ} \mathrm{C}$ in an incubated rotary shaker at $200 \mathrm{rpm}$. An active culture (from the late exponential phase) containing at least $10^{9}$ cells $\mathrm{cm}^{-3}$ was added to the sterilized ASWNB medium amounting to $10 \%$ inoculum and was used for subculturing. To obtain cell-free spent growth medium a fully-grown batch culture was centrifuged at $17700 \mathrm{~g}$ at $10^{\circ} \mathrm{C}$ followed by pressure filtration through a sterile $0.2 \mu \mathrm{m}$ Millipore filter. The visual absence of any cells in the resultant spent growth medium was confirmed by examination under a phase contrast microscope.

\subsection{UV-visible spectroscopic studies with the spent growth medium from Bacillus M1}

To determine UV spectra of the spent medium at a $\mathrm{pH}$ of 8 , an uninoculated medium at the same $\mathrm{pH}$ value was taken as reference. For studies with the spent growth medium having a $\mathrm{pH}$ value of 10,11 or 12 , spent growth medium at a $\mathrm{pH}$ of 8.0 was used as the reference to obtain the difference spectra. A Simadzu model UV-260, UV-visible spectrophotometer was employed for all theses studies.

\subsection{Leaching experiments}

For leaching studies, $1 \mathrm{~g}$ of pulverized ocean nodules was added to $100 \mathrm{~cm}^{3}$ of the spent growth medium to keep the solid:liquid ratio at $1: 100(\mathrm{w} / \mathrm{v})$, ie $1 \%$ pulp density, and leaching was continued for $10 \mathrm{~h}$. The recovery of different metals in the leach liquor was monitored as a function of time.

\subsubsection{Effect of $p H$}

The initial $\mathrm{pH}$ of the spent growth medium was in the range of 8-8.5. The effect of initial $\mathrm{pH}$ on leaching efficiency was investigated by varying the $\mathrm{pH}$ using $0.01 \mathrm{~mol} \mathrm{dm}^{-3} \mathrm{H}_{2} \mathrm{SO}_{4}$ or $0.01 \mathrm{~mol} \mathrm{dm}^{-3} \mathrm{NaOH}$ solutions.

\subsubsection{Series leaching experiments}

Multistep leaching experiments with the spent growth medium from the marine isolate culture consisted of four cycles in succession, as shown in Fig 1.

In two-step leaching experiments, the first cycle consisted of leaching with the spent growth medium from the marine isolate culture. After $4 \mathrm{~h}$ of the leaching cycle, the residue was filtered, dried and was used as feed for the second stage. The second cycle consisted of leaching in (a) spent growth medium from an $A$ thiooxidans culture and (b) sulfuric acid solution having a $\mathrm{pH}$ of 2.0, to get benefit from the low $\mathrm{pH}$ value. A strain of $A$ thiooxidans (MCM B41) was used in this study. It was obtained from the Maharashtra Association for Cultivation of Science (MACS), Pune, India. The organism was subcultured in the laboratory using modified $9 \mathrm{~K}$ basal medium, $1 \mathrm{dm}^{3}$ of which contained $0.25 \mathrm{~g}$ dipotassium dihydrogen phosphate, $0.5 \mathrm{~g}$ magnesium sulfate, $2 \mathrm{~g}$ ammonium sulfate and $10 \mathrm{~g}$ sulfur powder. After $72 \mathrm{~h}$, the culture was centrifuged in a Sorvall RC-5B refrigerated high-speed centrifuge at a force of $17700 \mathrm{~g}$ for $10 \mathrm{~min}$ at $5^{\circ} \mathrm{C}$ to obtain cell-free spent growth medium.

\subsubsection{Leaching with spent growth medium to which starch was added}

Analytical grade soluble starch (potato) was added directly to the spent growth medium cultures from 


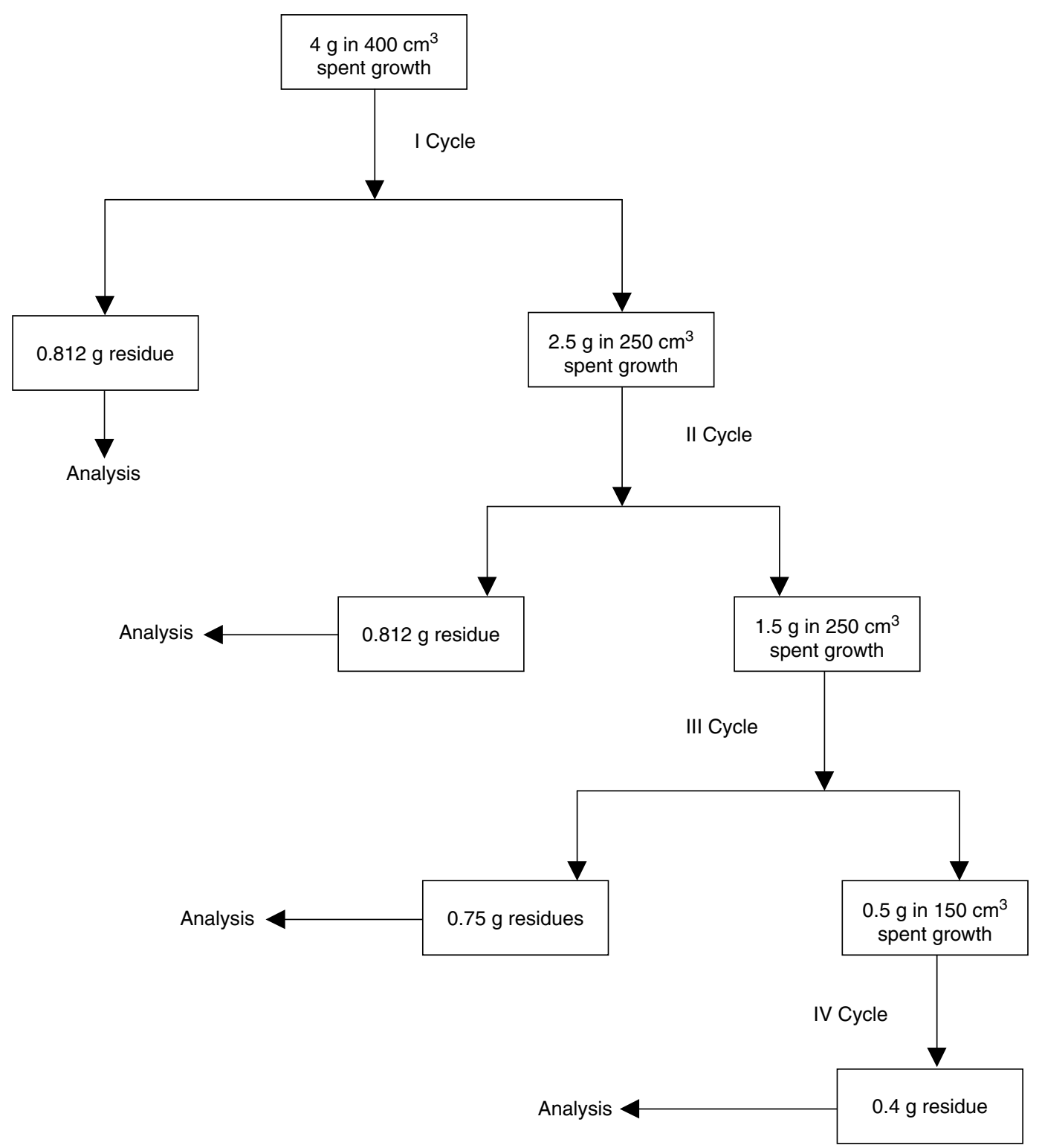

Figure 1. Flow scheme of the four-cycle leaching process of ocean nodules using spent growth medium of the marine isolate.

the Bacillus M1 culture in varying amounts and the nodules at $1 \%$ pulp density were leached for $4 \mathrm{~h}$.

In all the above cases, leach liquor was collected after appropriate lengths of contact with crushed nodules used for leaching and filtered using Whatman No 42 filter papers. The residue was then digested in $1: 1 \mathrm{HCl}$ at $60-70^{\circ} \mathrm{C}$. The resultant solution was analyzed after appropriate dilutions for $\mathrm{Cu}, \mathrm{Co}, \mathrm{Ni}, \mathrm{Mn}$ and $\mathrm{Fe}$ by using a Jobin Yvon JY 24, inductively coupled plasma spectrometer.

\section{RESULTS AND DISCUSSION}

\subsection{Control leaching experiments with spent growth medium}

The result of a control leaching experiment using spent growth medium from the marine isolate having a $\mathrm{pH}$ of 8.2 is illustrated in Fig 2 . Within $4 \mathrm{~h}$, almost $45 \% \mathrm{Co}$ and $\mathrm{Fe}$, and $25 \% \mathrm{Mn}$ had been leached whereas $20-25 \% \mathrm{Cu}$ and $\mathrm{Ni}$ were solubilized in $5-6 \mathrm{~h}$.

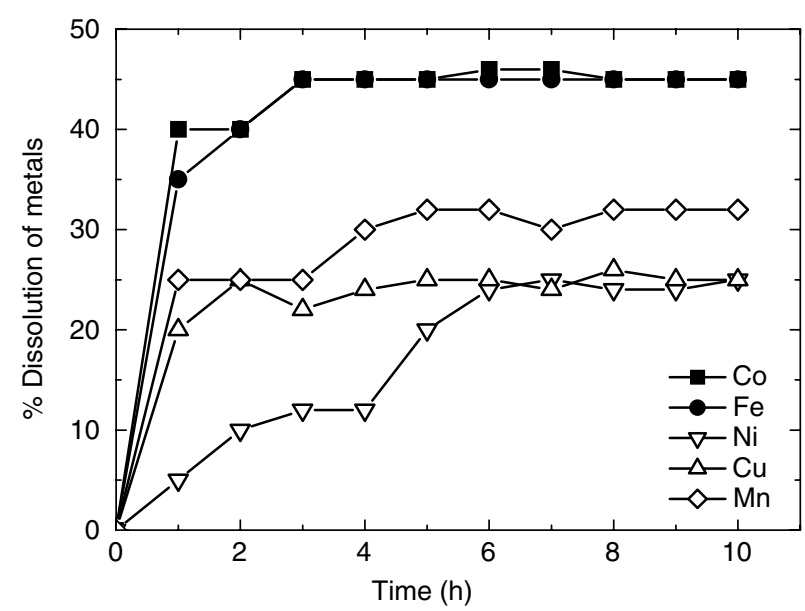

Figure 2. Kinetics of metal dissolution in bioleaching with the spent growth medium from the marine isolate.

Detailed characterization studies on the spent growth medium revealed the presence of phenolic substances 
having attached carboxylic acid groups, which are known complexation agents for transition metals. ${ }^{8}$ The probable mechanism of metal dissolution by the spent growth medium at near neutral $\mathrm{pH}$ has been discussed elsewhere (Mukherjee A, unpublished).

\subsection{Effect of modifications in $\mathrm{pH}$ of the spent growth medium from Bacillus M1 culture}

The effects on bioleaching, of gradually increasing the $\mathrm{pH}$ of the spent growth medium from 8 to 12 were investigated. No significant changes were observed in metal dissolution in a $\mathrm{pH}$ range from 8 to 10 , whereas on increasing the $\mathrm{pH}$ to 12 , a $20-25 \%$ increase in the dissolution of $\mathrm{Cu}, \mathrm{Co}$ and $\mathrm{Ni}$ was noted.

UV-visible spectroscopy of the spent growth medium at $\mathrm{pH} 8$ showed two peaks, one near $230 \mathrm{~nm}$ and another at $310 \mathrm{~nm}$. Chakravarty et al ${ }^{9}$ isolated and partially characterized a catechol-type siderophore compound produced by Pseudomonas stutzeri grown under iron-depleted conditions. The purified siderophore revealed UV spectra $(230 \mathrm{~nm}$ and $330 \mathrm{~nm}$ bands) which were found to be identical with that of 2,3-DHBA (dihydroxy benzoic acid). In another characterization study with siderophores O'Brien and Gibson ${ }^{10}$ isolated five compounds from culture media of Escherichia coli and Aerobacter aerogenes under conditions of iron deficiency. The compound named 2,3-dihydroxy- $N$-benzoylserine gave two distinct UV peaks in water, one near $315 \mathrm{~nm}$ and the other near $310 \mathrm{~nm}$. Therefore the presence of absorption peaks near 230 and $308 \mathrm{~nm}$ strongly suggests a DHB (dihydroxy benzoate) structure.

The enhancement in metal dissolution above $\mathrm{pH}$ 12 might be due to a change in structure of the metabolites, which may intensify the complexation effect. To confirm structural changes, UV-visible difference spectra of the spent growth medium from the isolate were recorded at $\mathrm{pH}$ values above 10, with respect to spent growth medium having a $\mathrm{pH}$ of 8 , and the results are summarized in Table 1 . Increasing the $\mathrm{pH}$ of the spent growth medium clearly caused a change in the UV spectra, suggesting a structural change in the metabolites in the medium. Displacement of a benzene band can be caused either by electron-contributing or by electron-attracting influences in the constituent groups. A shift of the $310 \mathrm{~nm}$ band to a lower wavelength of $298 \mathrm{~nm}$ in a very high alkaline $\mathrm{pH}$ range may be attributed to the ionization of a group(s) attached to the benzene ring, probably diminishing a tendency for electron transfer to or from the ring.

A titration curve of the spent growth medium with $0.01 \mathrm{~mol} \mathrm{dm}^{-3} \mathrm{NaOH}$ is shown in Fig 3. The $\mathrm{p} K_{\mathrm{a}}$ value for the spent growth medium was observed to lie between 10.5 and 11.0 , confirming a state of deprotonation of the metabolites above that $\mathrm{pH}$ range. So the deprotonated structure of the metabolite(s) in the spent growth medium could have enhanced their complexation efficiency.
Table 1. Change in UV spectra of the spent growth medium with increase in $\mathrm{pH}$ from 8 to 12

\begin{tabular}{lccc}
\hline & \multicolumn{3}{c}{$\begin{array}{c}\text { Recorded peak positions (nm) } \\
\text { (absorbance given in parentheses) }\end{array}$} \\
\cline { 2 - 4 } pH of spent & $\begin{array}{c}\text { 220-230 } \\
\text { growth medium }\end{array}$ & $\begin{array}{c}\text { 250-290 } \\
\text { range }\end{array}$ & $\begin{array}{c}290-300 \\
\text { range }\end{array}$ \\
\hline 8 & 233.8 & & 308.2 \\
10.5 & - & - & $298.8(0.551)$ \\
11 & - & & $297.4(0.449)$ \\
11.5 & & - & $298.7(0.642)$ \\
12 & - & & $299.0(0.849)$ \\
\hline
\end{tabular}

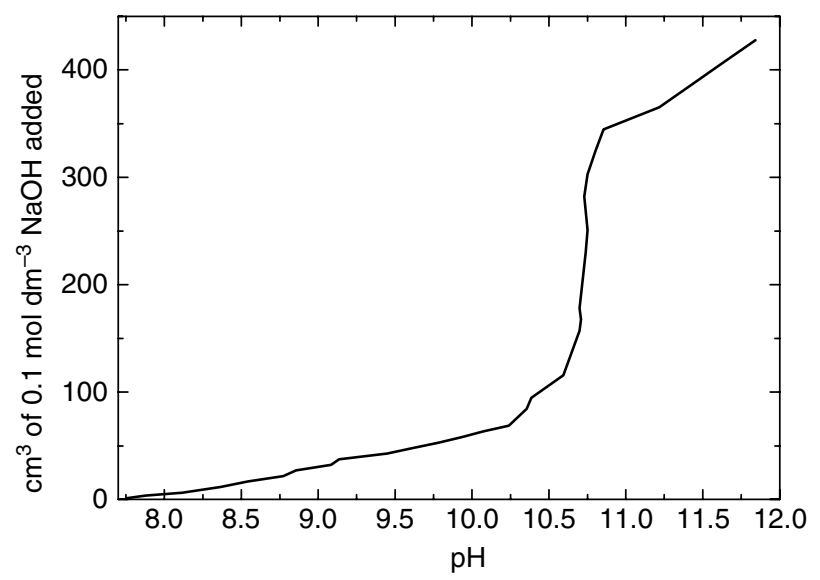

Figure 3. Titration curve of the spent growth medium in the $\mathrm{pH}$ range of 8 to 12 using $0.01 \mathrm{~mol} \mathrm{dm}^{-3} \mathrm{NaOH}$.

\subsection{Changes in the process design - series leaching}

In order to improve metal dissolution, multistep leaching experiments were conducted using spent growth medium of the marine isolate. The results are shown in Table 2. In these experiments the leached residue from the first cycle of leaching was put through subsequent leaching cycles to determine if fresh spent growth medium could help in recovering the metal values remaining in the residue. After four cycles of leaching, each of a $4 \mathrm{~h}$ duration, around $87 \%$ Co, $90 \%$ $\mathrm{Fe}, 60 \% \mathrm{Cu}$ and $\mathrm{Ni}$, and $70 \% \mathrm{Mn}$ were dissolved.

In multistep leaching experiments with the spent growth medium, recovery values in each cycle signified the fraction of total metal values that was added before the first leaching cycle. If the starting concentration

Table 2. Metal dissolution from ocean nodules using spent growth medium in four-stage leaching process

\begin{tabular}{lrrrrr}
\hline & \multicolumn{5}{c}{ \% Dissolution of metals } \\
\cline { 2 - 6 } Conditions of leaching & Co & Cu & Ni & Mn & Fe \\
\hline Cycle I & 45 & 25 & 23 & 27 & 50 \\
Cycle II & 23 & 17 & 16 & 18 & 24 \\
Cycle III & 12 & 12 & 12 & 13 & 11 \\
Cycle IV & 5 & 9 & 8 & 12 & 5 \\
Cycle I + Cycle II + & 85 & 63 & 59 & 70 & 90 \\
$\quad$ Cycle III + Cycle IV & & & & & \\
\hline
\end{tabular}


of Co was $100 \mathrm{ppm}$, the recovery in the first cycle of leaching was $45 \mathrm{ppm}$, in the second one $23 \mathrm{ppm}$, the third cycle recovered $12 \mathrm{ppm}$ and in the last cycle, recovery was only $5 \mathrm{ppm}$, total recovery was $85 \mathrm{ppm}$ at the end of four cycles, signifying $85 \%$ recovery.

Although multistep leaching in spent growth medium from the marine isolate dissolved considerable amounts of metal at $1 \%$ pulp density, the process has certain limitations, such as:

(a) Leaching in four steps would take nearly $20 \mathrm{~h}$ taking into consideration the time usually spent between two successive leaching cycles.

(b) $\mathrm{Cu}$ and $\mathrm{Ni}$ recovery values were below $65 \%$.

In view of the above limitations, studies were performed with fewer re-leaching steps. Some leaching experiments were performed in two steps in which the first cycle in spent growth medium from the marine isolate was followed by re-leaching the residue at a low $\mathrm{pH}$. The low-pH environment was induced by both biological and non-biological means. Low-pH leaching agents such as $\mathrm{pH} 2$ sulfuric acid solutions and spent growth medium from $A$ thiooxidans were employed for re-leaching.

The basic idea behind using the second cycle of leaching in acidic media was to:

(i) Enhance solubility of metal ions in a low-pH environment.

(ii) Use the sulfate ions present in spent growth medium from $A$ thiooxidans culture to solubilize metals in nodule material.

The results from such two-step leaching experiments are shown in Table 3. The dissolution of metals was taken as a fraction of total metal content in the nodules (as obtained from the initial chemical composition) at each individual step. The sum of the metal dissolution at stages 1 and $2 \mathrm{~A}$, respectively, gives total recovery by a two-step leaching process, when residue from the leaching in spent growth medium of Bacillus $\mathrm{M} 1$ is re-leached in $\mathrm{pH} 2$ solutions. Similarly, adding up the metal dissolution values in stages 1 and $2 \mathrm{~B}$ respectively, we obtain the total solubilization, when leaching in spent growth medium of Bacillus M1 is followed by that in the spent growth medium of $A$ thiooxidans.

In the case of $1 \%$ pulp density, total dissolution after two-step leaching in $A$ thiooxidans spent growth medium were $85 \% \mathrm{Co}, 90 \% \mathrm{Cu}$ and $60 \% \mathrm{Ni}$. Re-leaching in $\mathrm{pH} 2$ solutions yielded less metal dissolutions in two steps compared with that in the spent growth medium from $A$ thiooxidans. Notably, both $\mathrm{pH} 2$ solutions and the spent growth medium from $A$ thiooxidans dissolved more $\mathrm{Fe}$ in comparison to $\mathrm{Mn}$ in the re-leaching step. When the pulp density was increased to $5 \%$ in the case of two-step leaching, the metal dissolution increased correspondingly.

\subsection{Effect of adding starch to the spent growth medium from Bacillus M1}

In the extensively-discussed hypochlorite oxidation of starch, researchers ${ }^{11}$ observed that the reaction rate was markedly influenced by $\mathrm{pH}$. The reaction rate was found to be most rapid in slightly acidic and basic solutions while it slowed down in a highly alkaline or acidic $\mathrm{pH}$ range. Since the typical $\mathrm{pH}$ values of leaching with the spent growth medium fell within the neutral range, starch was chosen as a reductant for enhancing metal dissolution.

Oxidants such as potassium permanganate, persulfate, chlorite and hydrogen peroxide have been used to bleach starch. Mn(IV) oxide is also a powerful oxidant.

$$
\begin{aligned}
& \frac{1}{2} \delta \mathrm{MnO}_{2}(\mathrm{~s})+2 \mathrm{H}^{+}+\mathrm{e}^{-} \longrightarrow \frac{1}{2} \mathrm{Mn}^{2+}+2 \mathrm{H}_{2} \mathrm{O} \\
& E h=1.0488 \mathrm{~V}
\end{aligned}
$$

The nodules consist of $\mathrm{Mn}$ (IV) oxide as a major phase; therefore starch can be applied as a possible agent for reductive dissolution.

The reduction potential of $1 \%$ starch solution in the spent growth medium was observed to be $-0.045 \mathrm{~V}$ (wrt Saturated Calomel Electrode). From eqn (1) the $E h$ value corresponding to $\mathrm{Mn}(\mathrm{IV})$ reduction is $1.0488 \mathrm{~V}$. This large difference in $E h$ values ensured the reducibility of $\mathrm{MnO}_{2}$ by starch in spent growth medium.

Table 4 illustrates the effect of increasing the concentration of starch from $0.1 \%$ to $10 \%$ in the spent growth medium of Bacillus M1 as described below:

(i) Adding starch to spent growth medium from the marine isolate enhanced dissolution of metals from the nodules. Leaching in unamended spent growth medium alone at $1 \%$ pulp density brought about $45 \% \mathrm{Co}$ and around $25 \% \mathrm{Cu}$ and $\mathrm{Ni}$ into solution. Adding 3\% starch to the spent growth

\begin{tabular}{|c|c|c|c|c|c|c|c|}
\hline \multirow{2}{*}{$\begin{array}{l}\text { Pulp } \\
\text { density }\end{array}$} & \multirow{2}{*}{$\begin{array}{c}\text { Leaching } \\
\text { stage }\end{array}$} & \multirow[b]{2}{*}{ Leaching medium } & \multicolumn{5}{|c|}{$\%$ Dissolution of metals } \\
\hline & & & Co & $\mathrm{Cu}$ & $\mathrm{Ni}$ & $\mathrm{Mn}$ & $\mathrm{Fe}$ \\
\hline \multirow[t]{3}{*}{$1 \%$} & 1 & Bacillus M1 spent growth medium & 45 & 20 & 29 & 25 & 45 \\
\hline & $2 \mathrm{~A}$ & pH 2 solution & 30 & 30 & 39 & 5 & 40 \\
\hline & $2 \mathrm{~B}$ & A thiooxidans spent growth medium & 40 & 70 & 38 & 2 & 45 \\
\hline \multirow[t]{3}{*}{$5 \%$} & 1 & Bacillus M1 spent growth medium & 50 & 20 & 25 & 25 & 50 \\
\hline & $2 \mathrm{~A}$ & $\mathrm{pH} 2$ solution & 30 & 27 & 30 & 8 & 39 \\
\hline & $2 \mathrm{~B}$ & A thiooxidans spent growth medium & 40 & 70 & 39 & 8 & 45 \\
\hline
\end{tabular}

Table 3. Metal dissolution in each step of different two-stage leaching processes 
Table 4. The effect of adding starch to the spent growth medium on leaching of ocean nodules

\begin{tabular}{|c|c|c|c|c|c|}
\hline \multirow[b]{2}{*}{ Leaching reagent } & \multicolumn{5}{|c|}{$\%$ Dissolution of metals } \\
\hline & Co & $\mathrm{Cu}$ & $\mathrm{Ni}$ & $\mathrm{Mn}$ & $\mathrm{Fe}$ \\
\hline $\begin{array}{l}\text { Spent growth medium only } \\
\text { (marine isolate) }\end{array}$ & 45 & 20 & 29 & 25 & 45 \\
\hline $\begin{array}{l}\text { Spent growth medium + } \\
0.1 \% \text { starch }\end{array}$ & 65 & 35 & 35 & 30 & 50 \\
\hline $\begin{array}{l}\text { Spent growth medium + } \\
0.5 \% \text { starch }\end{array}$ & 85 & 70 & 60 & 83 & 80 \\
\hline $\begin{array}{l}\text { Spent growth medium + 1\% } \\
\text { starch }\end{array}$ & 80 & 80 & 65 & 85 & 86 \\
\hline $\begin{array}{l}\text { Spent growth medium }+3 \% \\
\text { starch }\end{array}$ & 80 & 83 & 82 & 83 & 85 \\
\hline $\begin{array}{l}\text { Spent growth medium + 5\% } \\
\text { starch }\end{array}$ & 83 & 85 & 86 & 87 & 84 \\
\hline $\begin{array}{l}\text { Spent growth medium + } \\
10 \% \text { starch }\end{array}$ & 84 & 88 & 87 & 85 & 87 \\
\hline
\end{tabular}

medium enhanced the dissolution values up to $80-85 \%$.

(ii) No further increases in metal solubilization were noted above $3 \%$ starch in the spent growth medium.

Fe dissolution by starch was almost double the Mn dissolution in all the cases. The reductant to metal oxide molar ratio was higher in the case of $\mathrm{Fe}$ since $\mathrm{Mn}$ concentration in the nodules was three to four times greater than $\mathrm{Fe}$ concentration. According to some schools of thought, Co may be associated with an $\mathrm{Fe}$ (III) oxide phase; ${ }^{1}$ therefore higher Co dissolution may be a direct consequence of higher $\mathrm{Fe}$ dissolution in solution. In the case of leaching with $0.1 \%$ starch in growth medium lower recovery of $\mathrm{Cu}$ and $\mathrm{Ni}$ is corroborated with low $\mathrm{Mn}$ recovery. At higher concentrations of starch in the spent growth medium Mn solubilization was enhanced, resulting in a concurrent rise in $\mathrm{Cu}$ and $\mathrm{Ni}$ dissolution. A direct correlation of $\mathrm{Cu}$ and $\mathrm{Ni}$ with $\mathrm{Mn}$ in the ocean nodules is well supported in the literature. ${ }^{1,12,13}$

\section{CONCLUSIONS}

The following major conclusions can be drawn based on the above study:

1. Changing the $\mathrm{pH}$ of the spent growth medium from the initial $\mathrm{pH}$ of 8 up to $\mathrm{pH} 10$ did not affect metal dissolution. However, increasing the $\mathrm{pH}$ of the spent growth medium to above 11 led to a $20-25 \%$ increment in dissolution of $\mathrm{Co}, \mathrm{Cu}$ and Ni. This could be related to a concomitant change in structure of the metabolite products present therein. The $\mathrm{p} K_{\mathrm{a}}$ value for the spent growth medium was found to lie within the range of $\mathrm{pH}$ 10.5-11.0.

2. A four-cycle step leaching in spent growth medium from Bacillus M1 dissolved about $85-90 \%$ Co and $\mathrm{Fe}, 70 \% \mathrm{Mn}$, and $60 \% \mathrm{Cu}$ and $\mathrm{Ni}$ in solution.

3. In a two-step bioleaching process about $80-85 \%$ dissolution of $\mathrm{Cu}, \mathrm{Co}$ and $\mathrm{Ni}$ was obtained by re-leaching the leached residue in spent growth medium from $A$ thiooxidans. When $\mathrm{pH} 2 \mathrm{H}_{2} \mathrm{SO}_{4}$ solution was used as leaching agent in the second step, nearly $50 \%, 75 \%, 68 \%$ dissolution of $\mathrm{Cu}$, Co and Ni respectively was obtained at $1 \%$ pulp density.

4. Addition of starch to the spent growth medium enhanced metal dissolution by reductive dissolution of major oxide phases. With 3\% starch in the spent growth medium around $80 \%$ of $\mathrm{Cu}, \mathrm{Ni}, \mathrm{Co}$ and Mn could be dissolved.

\section{REFERENCES}

1 Burns RG and Fuerstenau DW, Electron probe determinations of interelement relationships in manganese nodules. Amer Mineral 51:891-902 (1966).

2 Konishi Y, Asai S and Sawada Y, Leaching of marine manganese nodules by acidophilic bacteria growing on elemental sulfur. Metall Mater Trans 28B:25-32 (1987).

3 Kumari A and Natarajan KA, Electrobioleaching of polymetallic ocean nodules. Hydrometallurgy 62:125-134 (2001).

4 Ehrlich HL, Bacteriology of manganese modules I. Bacterial action on manganese in nodule enrichments. Applied Microbiol 16:197-202 (1963).

5 Ehrlich HL, Reactions with manganese by bacteria from marine ferromanganese nodules. Developments in Industrial Microbiology 7:43-60 (1966).

6 Ehrlich HL, Ghirose WC and Johnson II GL, Distribution of microbes in manganese nodules from the Atlantic and Pacific Oceans. Developments in Industrial Microbiology 13:57-65 (1972).

7 Mukherjee A, Raichur AM, Modak JM and Natarajan KA, Bio-processing of Indian Ocean nodules using a marine isolate-effect of organics. Minerals Engg 16(7):651-657 (2003).

8 Mukherjee A, Raichur AM, Modak JM and Natarajan KA, Preferential solubilization of cobalt from Ocean nodules at neutral pH- A novel bioprocess. F Ind Microbiol Biotechnol 30:606-612 (2003).

9 Chakravarty RN, Patel HN and Desai SB, Isolation and partial characterization of catechol-type siderophore from Pseudomonas stutzeri RC 7. Curr Microbiol 20:283-286 (1990).

10 O'Brien IG and Gibson F, The structure of enterochelin and related 2,3 dihydroxy- $N$-benzoylserine conjugates from Escherichia coli. Biochim Biophys Acta 213:393-402 (1970).

11 Whistler RL and Schweiger R, Oxidation of amylopectin with hypochlorite at different hydrogen ion concentration. $7 \mathrm{Amer}$ Chem Soc 79:6460-6464 (1957).

12 Cronan DS and Tooms JS, Subsurface concretions of manganese nodules in Pacific sediments. Deep-sea Res 14:355-359 (1967)

13 Glasby GP, Mechanism of incorporation of manganese and associated trace elements in marine manganese nodules. Oceanogr Mar Biol Ann Rev 12:11-40 (1974). 